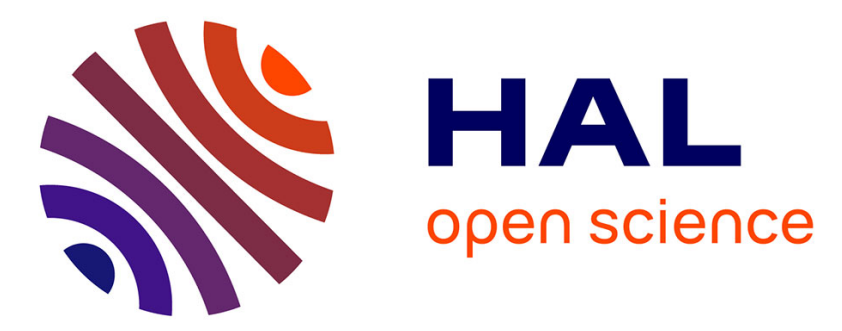

\title{
Using a second gradient model to simulate the behaviour of concrete structural elements
}

Gwendal Jouan, Panagiotis Kotronis, Frédéric Collin

\section{To cite this version:}

Gwendal Jouan, Panagiotis Kotronis, Frédéric Collin. Using a second gradient model to simulate the behaviour of concrete structural elements. Finite Elements in Analysis and Design, 2014, 90, pp.50-60. 10.1016/j.finel.2014.06.002 . hal-01071397

\section{HAL Id: hal-01071397 https://hal.science/hal-01071397}

Submitted on 11 Nov 2019

HAL is a multi-disciplinary open access archive for the deposit and dissemination of scientific research documents, whether they are published or not. The documents may come from teaching and research institutions in France or abroad, or from public or private research centers.
L'archive ouverte pluridisciplinaire HAL, est destinée au dépôt et à la diffusion de documents scientifiques de niveau recherche, publiés ou non, émanant des établissements d'enseignement et de recherche français ou étrangers, des laboratoires publics ou privés.

\section{다(1) $\$$}

Distributed under a Creative Commons Attribution - NonCommercial| 4.0 International 


\title{
Using a second gradient model to simulate the behaviour of concrete structural elements
}

\author{
Gwendal Jouan ${ }^{\mathrm{a}, \mathrm{b}}$, Panagiotis Kotronis ${ }^{\mathrm{a}, *}$, Frédéric Collin ${ }^{\mathrm{b}}$ \\ a LUNAM Université, Ecole Centrale de Nantes, Université de Nantes, CNRS UMR 6183, GeM (Institut de Recherche en Génie Civil et Mécanique), \\ 1 rue de la Noë, BP 92101, 44321 Nantes Cedex 3, France \\ ${ }^{\mathrm{b}}$ Département Argenco, Université de Liège, Institut de mécanique et Génie Civil, Bât. 521 Chemin des chevreuils, B-4000 Liège 1, Belgium
}

\begin{abstract}
Being a quasi-brittle material, concrete under tensile loading exhibits a strain softening behaviour that cannot be accurately reproduced with classical (without an internal length parameter) continuum mechanics models. An internal length parameter must be introduced to regularize the problem, as in the case of the so-called second gradient model. In this approach, an enriched kinematic description of the continuum is adopted considering higher (second) order gradients of the displacements following the work of Cosserat, Toupin, Mindlin and Germain. The model has been developed by Chambon and co-workers and has been mainly used with plasticity constitutive laws to reproduce the non-linear behaviour of soils. It is here applied for the first time to concrete and reinforced concrete specimens considering material laws based on the damage mechanics theory. The advantages and limitations of the approach are discussed, and possible improvements towards more realistic responses are suggested.
\end{abstract}

\section{Introduction}

Since the 70s [1-3] researchers study the strain localization in quasi-brittle materials, or more generally in materials exhibiting strain softening. Strain localization zones are clearly observed in experimental tests [4] and it is well known that they cannot be modelled with classical (without an internal length parameter) continuum mechanics models. Analytically, the differential operator becomes hyperbolic and an infinite number of solutions are possible. Numerically, the loss of ellipticity appears as a pathological mesh dependency of the results. These shortcomings are due to the lack of an internal length parameter in the continuum model that characterizes the width of the localization zone [5-11]. Different approaches exist in the literature to regularize the problem and to obtain objective numerical global (i.e. forces, displacements) and local (i.e. strains, stresses, internal variables) results. The first is important for design purposes and the second to deal for example with durability and crack propagation problems. The different approaches are briefly summarized hereafter (see also [12] for a more detailed literature review):

\footnotetext{
* Corresponding author.

E-mail addresses: Gwendal.Jouan@ec-nantes.fr (G. Jouan),

Panagiotis.Kotronis@ec-nantes.fr (P. Kotronis), f.collin@ulg.ac.be (F. Collin).
}

- Regularization based on energy: The principle is to keep the same fracture energy dissipated during the formation of cracks whatever the size of the finite element mesh [13-16]. For this, the post-peak behaviour of the adopted constitutive law is changed according to the size of the finite elements. This approach provides global results that may seem to be independent of the size of the mesh. Nevertheless, the localization zone is necessarily concentrated in one element (as in a classical continuum mechanics model without an internal length parameter) and thus local and global results are not objective. Results are also dependent on the orientation of the finite element mesh.

- Regularization based on time dependency: Viscous terms are introduced in the model that restore the ellipticity of the differential operator [17]. However, because this method does not introduce an internal length to control the width of the localization zone, severe mesh dependence is avoided for dynamic but not for quasi-static calculations [18].

- Regularization based on spatial dependency:

- Using a non-local integral type variable (i.e. on the damage parameter or on the equivalent strain for constitutive laws based on damage mechanics) [8]. For this integral type model, the interaction between material points across a crack [19] can still pose problems. Similar difficulties also exist for materials presenting a different behaviour in traction and compression (consider for example the interactions across the compression and traction zones for a concrete beam 
submitted to bending, see also Section 4). Different approaches can be found in the literature to deal with these problems, mainly consisting in modifying the adopted weight function either near the boundaries [20] or by introducing a dependence on the stresses [21]. Nevertheless, this last assumption implies that the internal length is no longer a constant material parameter but that it decreases with increasing loading. Furthermore, as is the case for the other regularization techniques, the ability of the method to reproduce accurately global and local results under size effect needs to be more thoroughly studied [22].

- Using strain gradients controlling the evolution of the internal variables (i.e. the second gradient of the plastic strain in the consistency condition and/or the flow rule) $[7,23]$. This type of model is shown to be equivalent to the integral type model [23].

- Alternatively, the nonlocal variable can be defined via an implicit gradient of the corresponding local variable, and is then the solution of a boundary value problem [24]. This type of model is shown to be equivalent to the integral type model [23].

- By taking into account gradient of internal variables (the damage variable in the case of damage models) in the energy [25-27]. The gradient term here acts as a penalization term for the cases of high localization.

- More recently, strainlocalization due to damage has been treated using the thick level set approach [28]. The level set separates the undamaged from the damaged zone while the damage variable and its growth are a function of the level set propagation. The force driving the damage front is nonlocal in the sense that it averages information over the thickness in the wake of the front [28].

- A rather natural way of introducing (indirectly) a length parameter in a continuum model is to account for the microstructure of the material. The general class of the so-called microstructured models or higher order continuum models allows for the description of the kinematics of the microstructure by using an additional tensor in the displacement field. Higher order continuum theories can be traced back to the works of the Cosserat et al. [29], Toupin [30] and Mindlin $[31,32]$ and have been generalized and properly formulated by Germain $[33,34]$ using the virtual power method.

In this paper, we choose to work with the second gradient model developed by Chambon and co-workers [35-39]. This model can be seen as a particular case of a higher order continuum (see Section 2) and has been mainly used till now to regularize problems involving strain localization in soils. It is used hereafter to concrete and reinforced concrete elements. The paper is structured as follows: the theoretical framework of the second gradient model and its numerical implementation are at first presented. The objectivity of the numerical results is shown for a $1 \mathrm{~d}$ concrete specimen and the evolution of the localization zone is discussed. The paper ends with a case study, the simulation of a three point bending test on a reinforced concrete beam. Discussion on the numerical results shows the advantages and limitations of the approach that should be considered as a first step towards the use of local second gradient models for concrete structures.

\section{The second gradient model}

\subsection{Theoretical framework}

As detailed in the seminal work of Germain [33,34], using the virtual power method one can choose a field of virtual displacements to describe the proper kinematics of a higher order continuum including its microstructure. The internal stresses, limit conditions and equilibrium equations appear naturally as long as the linear form representing the virtual power is correctly defined and that it respects the principle of material independence.

The second gradient model developed by Chambon et al. $[35,36]$ can be seen as a particular case of a higher order continuum where up to second gradient terms are adopted and the macrostrains are considered to be equal to the microstrains. The authors have come to this assumption following experimental results that showed that for the case of geomaterials microrotations equal macrorotations $[40,41]$. They have presented case studies in the framework of plasticity and have shown that this type of model restores mesh objectivity but not the uniqueness of the solution [37-39,42].

For the second gradient model, the virtual displacement field must be chosen as a field of continuous and continuously differentiable velocities. According to the general theory for continua with microstructure presented in [37] and assuming that microstrains are equal to macrostrains, the virtual work principle equation takes the following form (for any $\alpha, \alpha^{\star}$ defining the virtual quantity). For the sake of simplicity, we neglect hereafter the body force terms and the presentation is done for a $2 \mathrm{~d}$ continuum:

$\int_{\Omega}\left(\sigma_{i j} \frac{\partial u_{i}^{\star}}{\partial x_{j}}+\Sigma_{i j k} \frac{\partial^{2} u_{i}^{\star}}{\partial x_{j} \partial x_{k}}\right) d \Omega=\int_{\Gamma}\left(p_{i} u_{i}^{\star}+P_{i} D u_{i}^{\star}\right) d \Gamma$,

with

- $i, j$ and $k$ (varying from 1 to 2 ),

- $x_{i}$ the coordinates,

- $u_{i}$ the macrodisplacements field,

- $D q$ the normal derivative of any quantity $q$ :

$$
D q=\frac{\partial q}{\partial x_{k}} n_{k}
$$

- $\sigma_{i j}$ the Cauchy stresses (macrostresses),

- $\Sigma_{i j k}$ the double stresses,

- $p_{i}$ the classical traction forces,

- $P_{i}$ the double traction forces,

- $\Gamma$ the boundary of $\Omega$.

The Cauchy stress $\sigma_{i j}$ is, as in classical continua, symmetric, the double stress $\sum_{i j k}$ is symmetric with respect to its indices $j$ and $k$. Application of the virtual work principle equation (1) and two integrations by parts provide the balance equation and the boundary conditions. The balance equations become

$\frac{\partial \sigma_{i j}}{\partial x_{j}}-\frac{\partial^{2} \Sigma_{i j k}}{\partial x_{j} \partial x_{k}}=0$

Assuming that the boundary is regular (which means existence and uniqueness of the normal for every point of the boundary $\Gamma$ of the studied domain), after one more integration by parts, we get

$\sigma_{i j} n_{j}-n_{k} n_{j} D \Sigma_{i j k}-\frac{D \Sigma_{i j k}}{D x_{k}} n_{j}-\frac{D \Sigma_{i j k}}{D x_{j}} n_{k}+\frac{D n_{l}}{D x_{l}} \Sigma_{i j k} n_{j} n_{k}-\frac{D n_{j}}{D x_{k}} \Sigma_{i j k}=p_{i}$,

and

$\sum_{i j k} n_{j} n_{k}=P_{i}$,

where $p_{i}$ and $P_{i}$ are prescribed. The tangential derivative of any quantity $q$ is defined by

$\frac{D q}{D x_{j}}=\frac{\partial q}{\partial x_{j}}-\frac{\partial q}{\partial x_{k}} n_{k} n_{j}$ 
To complete the equations of the problem two constitutive laws have to be introduced linking the static variables macrostresses $\sigma_{i j}$ and double stresses $\Sigma_{i j k}$ with the kinematic variables strains (first gradient of the displacements) $\partial u_{i} / \partial x_{j}$ and double strains (second gradient of the displacements). The two constitutive laws are usually supposed to be decoupled $[35,36]$. The first gradient law can be any classical constitutive law (e.g. based on damage mechanics or plasticity). The second gradient law is usually based on linear elasticity.

Following the work of Mindlin [31,32], the vector of double stresses for a bidimensional case has eight components and can be found considering the derivative of the strain energy with respect to the second gradient of the strains and symmetry of the tensor $[31,32,43]$. The obtained result is (where $\alpha^{1}, \alpha^{2}, \alpha^{3}, \alpha^{4}, \alpha^{5}$ are five independent constants in the general case of an isotropic material)

$\left\{\begin{array}{c}\dot{\Sigma}_{111} \\ \dot{\Sigma}_{112} \\ \dot{\Sigma}_{121} \\ \dot{\Sigma}_{122} \\ \dot{\Sigma}_{211} \\ \dot{\Sigma}_{212} \\ \dot{\Sigma}_{221} \\ \dot{\Sigma}_{222}\end{array}\right\}=\left[\begin{array}{cccccccc}\alpha^{12345} & 0 & 0 & \alpha^{23} & 0 & \alpha^{12} & \alpha^{12} & 0 \\ 0 & \alpha^{145} & \alpha^{145} & 0 & \alpha^{25} & 0 & 0 & \alpha^{12} \\ 0 & \alpha^{145} & \alpha^{145} & 0 & \alpha^{25} & 0 & 0 & \alpha^{12} \\ \alpha^{23} & 0 & 0 & \alpha^{34} & 0 & \alpha^{25} & \alpha^{25} & 0 \\ 0 & \alpha^{25} & \alpha^{25} & 0 & \alpha^{34} & 0 & 0 & \alpha^{23} \\ \alpha^{12} & 0 & 0 & \alpha^{25} & 0 & \alpha^{145} & \alpha^{145} & 0 \\ \alpha^{12} & 0 & 0 & \alpha^{25} & 0 & \alpha^{145} & \alpha^{145} & 0 \\ 0 & \alpha^{12} & \alpha^{12} & 0 & \alpha^{23} & 0 & 0 & \alpha^{12345}\end{array}\right]\left\{\begin{array}{l}\dot{\chi}_{111} \\ \dot{\chi}_{112} \\ \dot{\chi}_{121} \\ \dot{\chi}_{122} \\ \dot{\chi}_{211} \\ \dot{\chi}_{212} \\ \dot{\chi}_{221} \\ \dot{\chi}_{222}\end{array}\right\}$,

with

$\chi_{p q r}=\frac{\partial^{2} u_{p}}{\partial x_{q} \partial x_{r}}$

$\alpha^{12345}=2\left(\alpha^{1}+\alpha^{2}+\alpha^{3}+\alpha^{4}+\alpha^{5}\right)$,

$\alpha^{23}=\alpha^{2}+2 \alpha^{3}$,

$\alpha^{12}=\alpha^{1}+\alpha^{2} / 2$,

$\alpha^{145}=\alpha^{1} / 2+\alpha^{4}+\alpha^{5} / 2$,

$\alpha^{25}=\alpha^{2} / 2+\alpha^{5}$,

$\alpha^{34}=2\left(\alpha^{3}+2 \alpha^{4}\right)$.

As there is no clear physical definition of the different material constants and in order to simplify the equations the following particular case of the general isotropic form is proposed [39], where only one material parameter $B$ is adopted with

$\alpha^{1}=0$

$\alpha^{2}=B$

$\alpha^{3}=-B / 2$

$\alpha^{4}=B$

$\alpha^{5}=-B$

leading to

$\left\{\begin{array}{c}\dot{\Sigma}_{111} \\ \dot{\Sigma}_{112} \\ \dot{\Sigma}_{121} \\ \dot{\Sigma}_{122} \\ \dot{\Sigma}_{211} \\ \dot{\Sigma}_{212} \\ \dot{\Sigma}_{221} \\ \dot{\Sigma}_{222}\end{array}\right\}=\left[\begin{array}{cccccccc}B & 0 & 0 & 0 & 0 & B / 2 & B / 2 & 0 \\ 0 & B / 2 & B / 2 & 0 & -B / 2 & 0 & 0 & B / 2 \\ 0 & B / 2 & B / 2 & 0 & -B / 2 & 0 & 0 & B / 2 \\ 0 & 0 & 0 & B & 0 & -B / 2 & -B / 2 & 0 \\ 0 & -B / 2 & -B / 2 & 0 & B & 0 & 0 & 0 \\ B / 2 & 0 & 0 & -B / 2 & 0 & B / 2 & B / 2 & 0 \\ B / 2 & 0 & 0 & -B / 2 & 0 & B / 2 & B / 2 & 0 \\ 0 & B / 2 & B / 2 & 0 & 0 & 0 & 0 & B\end{array}\right]\left\{\begin{array}{l}\dot{\chi}_{111} \\ \dot{\chi}_{112} \\ \dot{\chi}_{121} \\ \dot{\chi}_{122} \\ \dot{\chi}_{211} \\ \dot{\chi}_{212} \\ \dot{\chi}_{221} \\ \dot{\chi}_{222}\end{array}\right\}$.

This expression derives from the strain energy density defined as (considering only the second gradient terms)

$W_{\chi}=\frac{B}{2}\left(2 \chi_{k i i} \chi_{j j k}-\chi_{k i i} \chi_{k j j}+2 \chi_{k j i} \chi_{k j i}-2 \chi_{k j i} \chi_{i j k}\right)$

It is shown in $[35,36,42]$ and in Section 3.3 that the material parameter $B$ is directly linked with the size and the evolution of the localization zone.

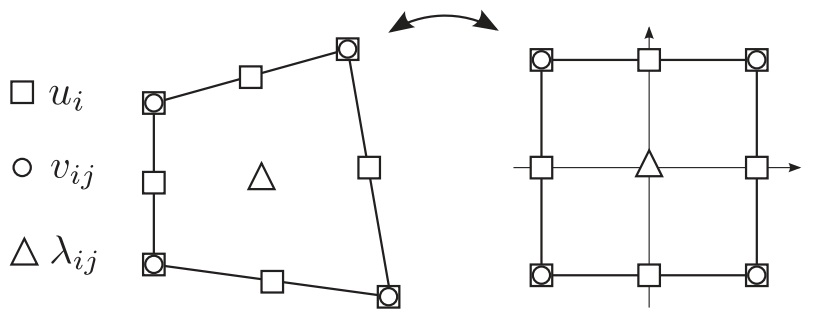

Fig. 1. The 2d second gradient finite element [44].

The second gradient model uses the gradient of kinematic variables. The constitutive equation remains local and so ideas and algorithms used in classical models can be adopted. Formulation of a second gradient extension for any classical model is thus straightforward.

\subsection{Numerical implementation}

The second gradient of the displacement necessitates the use of $C^{1}$ elements in a finite element code. This is avoided by introducing a new field of unknowns $v_{i j}$ imposed to be equal to the gradient of the displacements using Lagrange multipliers $\lambda_{i j}$ $[39,44]$. The new weak formulation of the problem then becomes

$\int_{\Omega} \sigma_{i j} \frac{\partial u_{i}^{\star}}{\partial x_{j}}+\Sigma_{i j k} v_{i j, k}^{\star} d \Omega-\int_{\Omega} \lambda_{i j}\left(\frac{\partial u_{i}^{\star}}{\partial x_{j}}-v_{i j}^{\star}\right) d \Omega=\int_{\Gamma}\left(p_{i} u_{i}^{\star}+P_{i} D u_{i}^{\star}\right) d \Gamma$,

$\int_{\Omega} \lambda_{i j}^{\star}\left(\frac{\partial u_{i}}{\partial x_{j}}-v_{i j}\right) d \Omega=0$

The problem is discretized using a nine (9) nodes finite element, where eight (8) nodes are used for the variables $u_{i}$, four (4) for $v_{i j}$ and one (1) node at the centre for the Lagrange multiplier $\lambda_{i j}$, see Fig. 1 . This element has been implemented in the finite element code LAGAMINE (University of Liège) and the problem is solved using the classical Newton-Raphson method [44].

\section{One-dimensional problem: objectivity of the results and evolution of the localization zone}

\subsection{Objectivity of the results}

The objectivity of the numerical results obtained with a second gradient model has been discussed in the past using constitutive laws for soils based on the mathematical theory of plasticity [37-39]. We study hereafter numerically the objectivity of the results for concrete specimens using constitutive laws based on damage mechanics.

Let us consider the case of one-dimensional traction applied on a concrete specimen. Fig. 2 shows the boundary conditions adopted for the $2 \mathrm{~d}$ second gradient finite element mesh introduced into the code LAGAMINE. In order to avoid possible $2 \mathrm{~d}$ effects, the vertical displacements $u_{2}$ are considered to be equal to zero at the upper and lower boundaries along the specimen. The section is considered to be equal to $0.1 \times 1 \mathrm{~m}^{2}$ and the length $1 \mathrm{~m}$. The right end of the specimen is fixed $\left(u_{1}=u_{2}=0\right)$ and the horizontal displacement $U$ is applied at the left end. The additional external double forces are assumed to be zero at both ends. As no global snap-back is expected with these material and geometrical parameters (see [36, Eq. (38)] for a snap-back criterion), the test is simply controlled by the imposed displacement.

The constitutive law linking the stresses with the strains is a classical damage mechanics law [45] with an initial slope 
$G^{e l}=30 \mathrm{GPa}$ and a slope at the peak $G^{\text {tg }}=-16.7 \mathrm{GPa}$ corresponding to a strain $\epsilon_{D 0}=1 \cdot \mathrm{e}^{-4}$, see Fig. 3(a). The constitutive law linking the double stresses with the second gradient of the displacements is based on linear elasticity and depends on a single parameter considered to be equal to $B=0.37 \mathrm{GN}$, see Fig. 3(b) and Section 2.1. The two constitutive laws are supposed to be decoupled.

Analytically, bifurcation in a 1D problem appears at the peak. In order to visualize different possible solutions, an algorithm of random initialization of the iterative solver of the equilibrium equation is applied just after the peak [46,47]. For every step, a full Newton-Raphson involving a numerical consistent tangent stiffness operator for the complete model (i.e. the second gradient terms as well as the classical ones) is used. The results of two meshes with 14 and 50 elements are presented hereafter [48].

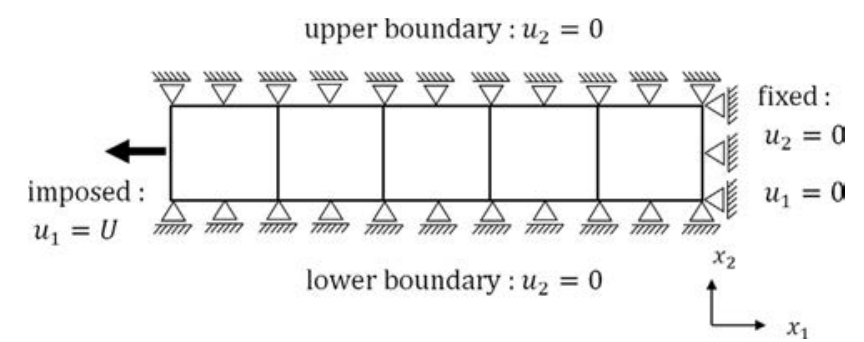

Fig. 2. Concrete specimen under 1D traction: boundary conditions and applied loading.
The convergence criterion and convergence rates are detailed in Section 3.2 .

Fig. 4 shows the global force versus displacement curve. The differences just after the peak correspond to distinct converged solutions. At the end of the loading, however, both meshes converge to the same solution.

The above remark can be better understood looking at the local results. Fig. 5 presents the distribution of the damage variable varying from 0 (undamaged section) to 1 (damaged section) - just after the peak, at a strain equal to $1.2 \mathrm{E}-04$. Fig. 6 presents the distribution of the damage variable at the end of the loading at a strain equal to $2.9 \mathrm{E}-04$. Just after the peak, the mesh with 14 elements converges to a solution with two patterns (a hard part and a soft (localized) part solution). The mesh with 50 elements converges to a three pattern solution (hard-soft (localized)-hard), Fig. 5. At the end of the loading, however, it switches to the same two-pattern solution as the mesh with 14 elements, Fig. 6. This phenomenon of switching deformation modes was also found to be using plasticity models in [49]. At the end of the loading the localization patterns and global curves provided by both meshes thus become identical.

From the above it is obvious that the use of the second gradient model with damage mechanics laws regularizes the problem (mesh independency) but does not restore the uniqueness of the solution for the corresponding boundary value problem. This was also found for constitutive laws based on plasticity $[47,49]$.

It is also observed in Fig. 4 that the non-homogeneous results at the end present a higher strength. Indeed, for the same end
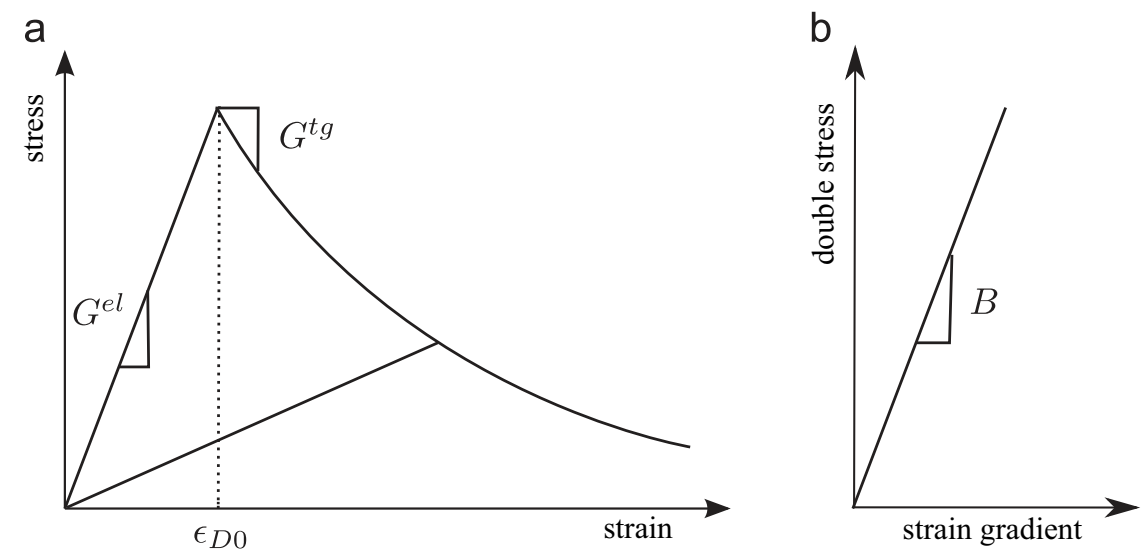

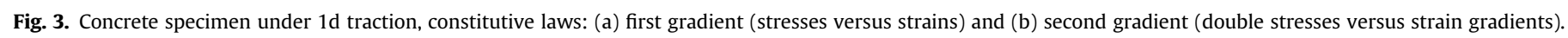

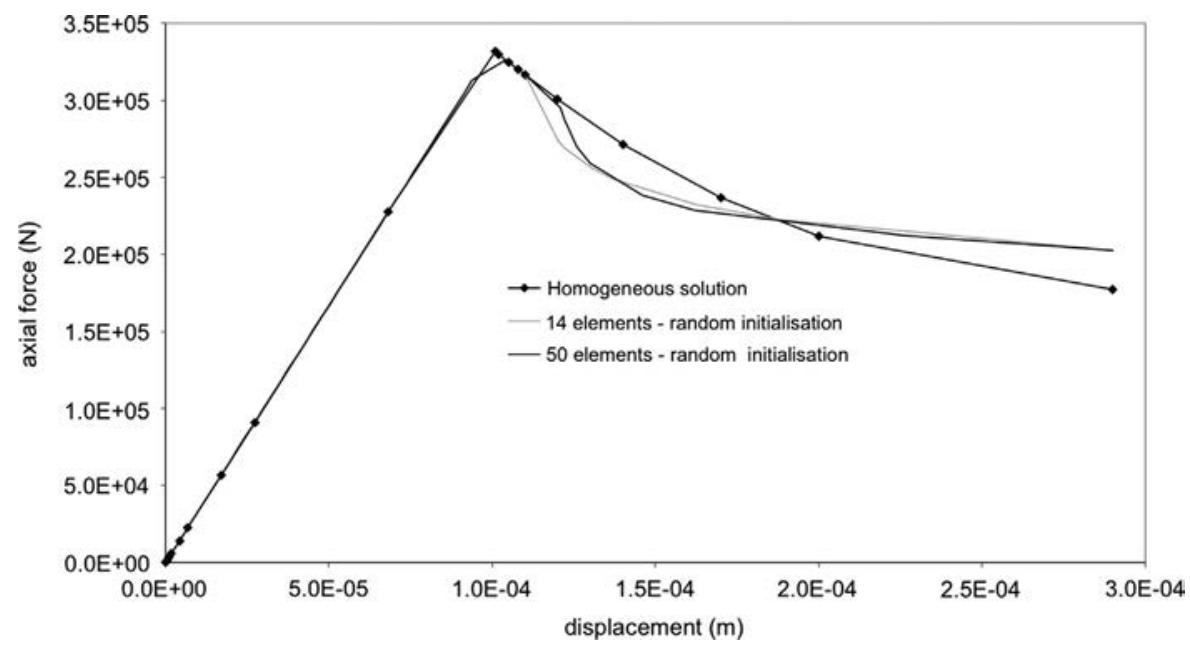

Fig. 4. Concrete specimen under 1d traction: force versus displacement curve. 
a

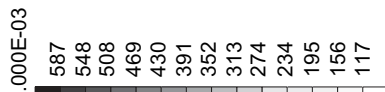

$\stackrel{\circ}{\circ}$

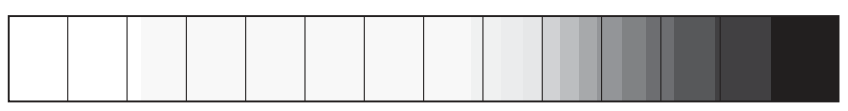

b

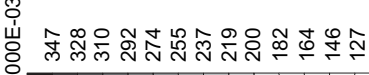

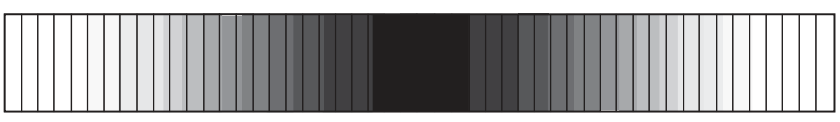

Fig. 5. Concrete specimen under 1d traction: distribution of the damage variable just after the peak (strain equal to $1.2 \mathrm{E}-04$ ): (a) 14 element mesh, (b) 50 element mesh.

a

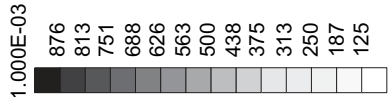

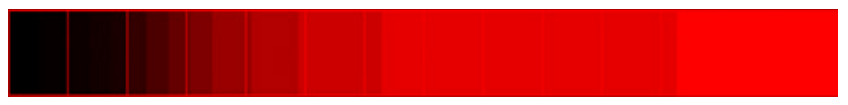

b

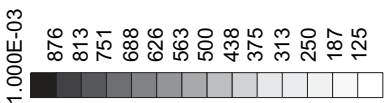

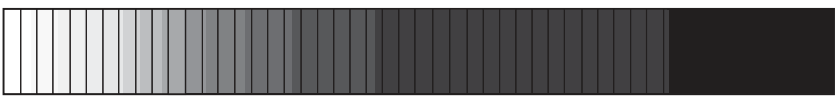

Fig. 6. Concrete specimen under 1d traction: distribution of the damage variable at the end of the loading (strain equal to $2.9 \mathrm{E}-04$ ): (a) 14 element mesh and (b) 50 element mesh.

displacement, the maximum stress is larger than that in the homogeneous case (see also [50]). An explanation of this numerical behaviour could be that the stiffness introduced by the second gradient terms does not vanish because of the adopted elastic law. A way to deal with this behaviour is to introduce a coupling between the first and second gradient material laws (something that can also help to a priori control the evolution of the localization zone, see [48] and Section 3.3). It can also be argued that at some point a displacement discontinuity must be introduced because the continuous damage model cannot model correctly a crack. In our case, this should be done by inserting a cohesive zone element since the discontinuity should be introduced before the damage reaches its maximum value. An approach like this is for example proposed for the case of a model with gradient of the internal variables by Cuvilliez et al. [51], see also [52-54].

\subsection{Numerical convergence}

Let $F^{\text {int }}$ and $F^{\text {ext }}$ be the internal and external nodal force vectors obtained from the finite element discretization of Eqs. (12) and (13) respectively. Also let $F^{o b f}$ be the out of balance forces defined by $F^{i n t}-F^{\text {ext }}$ and $F^{\text {react }}$ the vector of the forces associated with the fixed degrees of freedom. In the following, the forces associated with the displacement degrees of freedom are noted as $F\left(u_{i}\right)$, those associated with either the gradient or Lagrange multiplier degrees of freedom are noted as $F\left(v_{i j}, \lambda_{i j}\right)$. A norm for the force vectors is here adopted as the sum over the degrees of freedom of the absolute values of the vectors coordinates:

$\|F\|=\sum_{\operatorname{dof} i}\left|F_{i}\right|$

The convergence criterion for the nodal forces is met when

$\frac{1}{2}\left(\frac{\frac{\left\|F^{o b f}\left(u_{i}\right)\right\|}{N_{u}}}{\frac{\left\|F^{\text {react }}\left(u_{i}\right)\right\|}{N_{u}^{\text {react }}}}+\frac{\frac{\left\|F^{o b f}\left(v_{i j}, \lambda_{i j}\right)\right\|}{N_{v \lambda}}}{\frac{\left\|F^{\text {react }}\left(v_{i j}, \lambda_{i j}\right)\right\|}{N_{v \lambda}^{\text {react }}}}\right) \leq$ precision

where $N_{u}, N_{u}^{\text {react }}, N_{v \lambda}$ and $N_{v \lambda}^{\text {react }}$ are the number of degrees of freedom and the number of fixed degrees of freedom for the displacement field and both the gradient and Lagrange multipliers respectively. For the previous computation, the precision was set at $10^{-11}$. The convergence criterion proposed in Eq. (14) uses several different units (because of the different types of degrees of freedom). However, as specified in Eq. (15), the contribution of each degree of freedom has no dimensions, as far as the norm of the out of balance forces is divided by the norm of the reactions corresponding to the degree of freedom.

A typical convergence profile for the one dimensional traction test is shown in Fig. 7 starting from the random initialization. Convergence difficulties observed at the first step are a direct result of the random initialization [47]. The first few iterations for this step show an important error. However as soon as a solution is found, a classical convergence rate is recovered.

Convergence difficulties are also encountered seven steps after the random initialization (corresponding to around 70 total iterations). They correspond to a switching deformation mode [49]. Again, a classical convergence rate is recovered once the new localized solution is found.

\subsection{Evolution of the localization zone}

The internal length parameter does not appear clearly from the previous equations. However, an analytical solution exists for the 1d problem when a bilinear first gradient law and an elastic second gradient law are adopted [35,36]. The authors have proven that the solutions are built using patches of different fundamental solutions, consisting - as in Section 3 - of hard parts corresponding to the unloading (or elastically loading) pieces and soft parts for the loading pieces of the medium. Various analytical patterns are possible (a hard-soft solution, a soft-hard-soft solution, etc.) but their number is finite. This is not the case for a classical continuous mechanics medium without regularization where an infinite number of solutions are possible [42]. The analytical solution [35,36] introduces specific ratios for the hard $(\omega)$ and the soft pattern $(\eta)$

$\omega^{2}=\frac{G^{e l}}{B}>0$,

$-\eta^{2}=\frac{-G^{t g}}{B}>0$,

and a wavelength $l_{s}$ given by the following equation:

$l_{s}=2 \pi \sqrt{\frac{-B}{G^{t g}}}$.

This wavelength is proportional to the ratio of the moduli of the elastic second gradient law and of the softening branch corresponding to the first gradient law. It is only an indicator of the width of the localization zone, and it does not provide its exact value. This is due to the fact that it corresponds to a period of the soft part standing alone. The real solution being a patch of the different solutions $l_{s}$ is larger than the actual width [42]. 


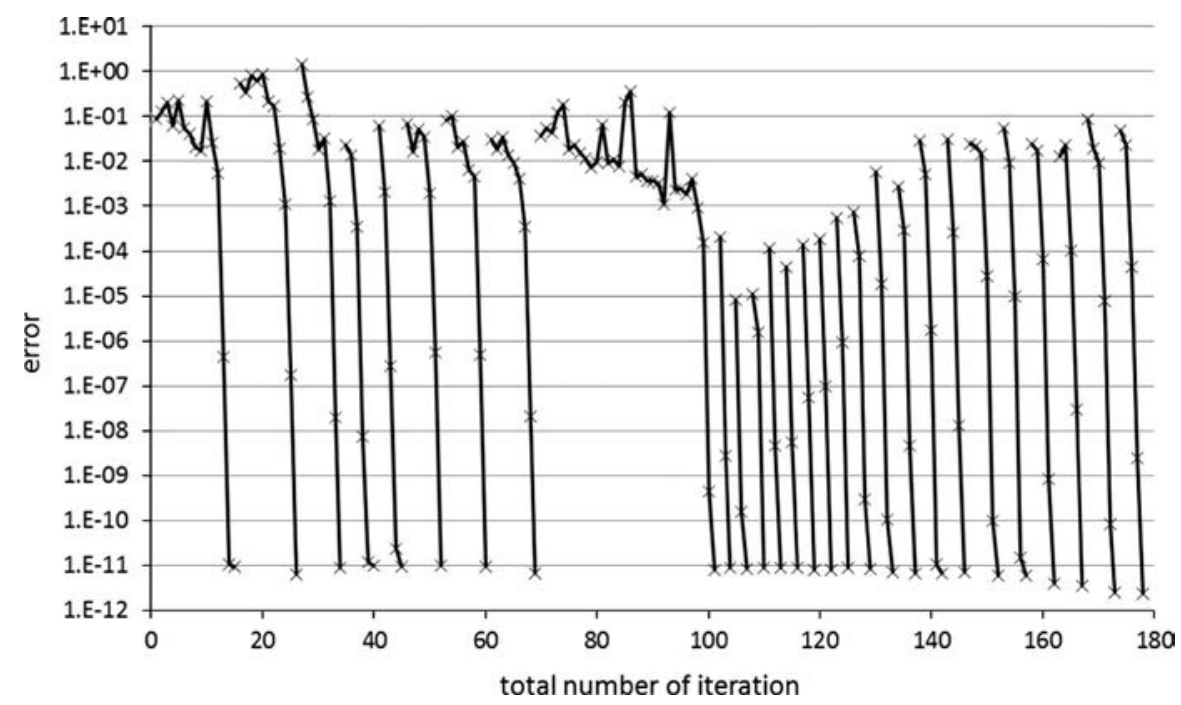

Fig. 7. Concrete specimen under $1 \mathrm{~d}$ traction: typical convergence profile.

Analytical equation (18) is valid for a $1 \mathrm{~d}$ problem considering a bilinear first gradient law and an elastic second gradient law. Nevertheless, it can be used to estimate the initial length of the localization zone and its evolution [42]. For concrete structural elements submitted to traction for example, constitutive laws have the general form of Fig. 3 [45]. As damage increases, the slope $G^{\text {tg }}$ of the stress strain curve diminishes (in absolute value) and the width of the band is thus found to be increased (see Figs. 5 and 6). For the case of compression, where concrete exhibits a more ductile behaviour the localization zone will at first decrease and then increase [42] (remark: a simplified 1d model to a priori control the evolution of the localization zone - constant, decreasing or increasing - is presented in [48] considering a coupling between the first and the second gradient law).

In the following section, an engineering case study is presented: the numerical simulation of a three point bending test on a reinforced concrete beam using the second gradient model.

\section{Three point bending test of a reinforced concrete beam}

\subsection{Experimental configuration}

A three point bending test was conducted on a reinforced concrete beam having the following geometrical characteristics: thickness $b=200 \mathrm{~mm}$, height $h=500 \mathrm{~mm}$ and span $5000 \mathrm{~mm}$. The geometry of the beam and informations about the steel reinforcement are shown in Fig. 8. A vertical cyclic load was applied at the upper part of the beam. Fig. 9 presents the positions of six strain gauges to monitor the axial strains on the steel bars.

\subsection{Finite element discretization}

The three point bending test is modelled hereafter as a two dimensional problem using the second gradient finite element described in Section 2.2. Two meshes have been used for the simulations, Fig. 10. The first mesh consists of 5180 elements, 4148 of which are second gradient elements and 1032 truss elements representing the horizontal reinforcement. The average size of the concrete elements for this mesh is of $0.02 \mathrm{~m} \times 0.035 \mathrm{~m}$. The second mesh consists of 13494 elements with an average size of $0.01 \mathrm{~m} \times 0.017 \mathrm{~m}$ for the concrete elements. Concrete and steel elements are supposed to be perfectly bonded (for engineering applications where we are mostly concerned with the behaviour of

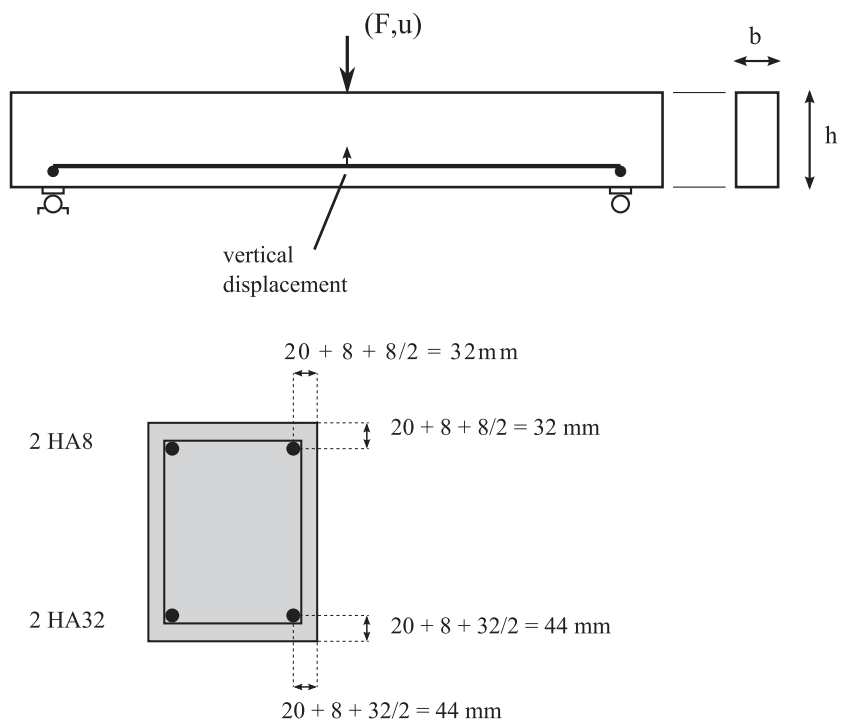

Fig. 8. 3 point bending test: beam dimensions and steel reinforcement $[55,56]$.

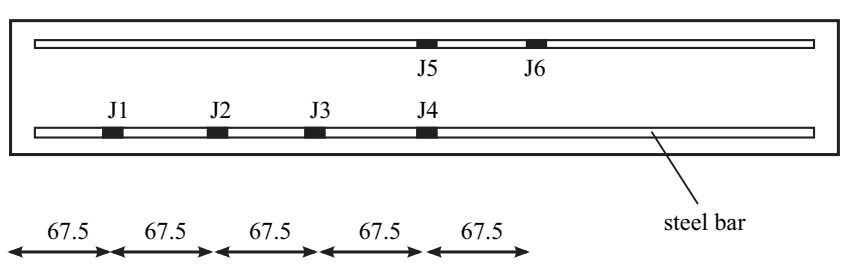

Fig. 9. 3 point bending test: position of the strain gauges $[55,56]$.

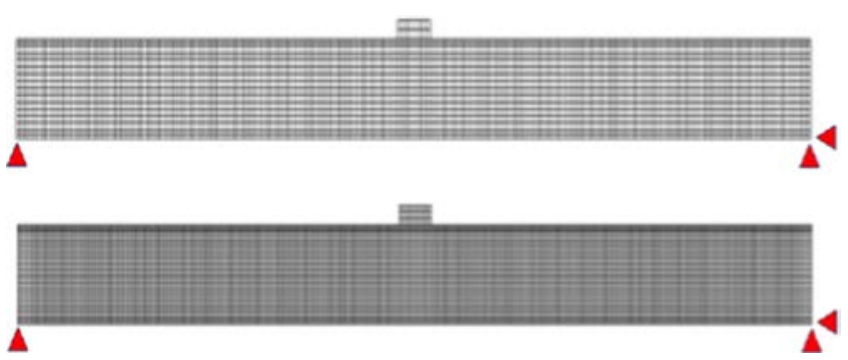

Fig. 10. 3 point bending test: finite element meshes and boundary conditions. 
Table 1

3 point bending test: concrete material parameters [45].

\begin{tabular}{lllllll}
\hline$E(\mathrm{GPa})$ & $\epsilon_{D 0}$ & $A_{t}$ & $B_{t}$ & $A_{c}$ & $B_{c}$ & $\beta$ \\
\hline 37.2 & $9.1 \mathrm{E}-05$ & 0.7 & 6800 & 0.42 & 780 & 1.1 \\
\hline
\end{tabular}

Table 2

3 point bending test: steel parameters (lower part).

\begin{tabular}{lll}
\hline$E(\mathrm{GPa})$ & $\sigma_{y}(\mathrm{MPa})$ & Section $\left(\mathrm{m}^{2}\right)$ \\
\hline 195 & 466 & $16.085 \mathrm{E}-04(2 \mathrm{HA} 32)$ \\
\hline
\end{tabular}

Table 3

3 point bending test: steel parameters (upper part).

\begin{tabular}{lll}
\hline$E(\mathrm{GPa})$ & $\sigma_{y}(\mathrm{MPa})$ & Section $\left(\mathrm{m}^{2}\right)$ \\
\hline 195 & 466 & $1.0053 \mathrm{E}-04(2 \mathrm{HA} 8)$ \\
\hline
\end{tabular}

a structure on the ultimate limit state (ULS) this assumption is acceptable $[57,58])$. The end nodes at each lower extremity of the beam are blocked vertically; the right node is blocked horizontally. For the finite element calculations, monotonically increased displacements are applied at the upper part of the beam through an elastic plate, which is very stiff compared to the other materials. At the supports at both ends of the beam and on the upper part, where the displacements are applied, an elastic linear law is introduced to prevent from artificial numerical damage.

\subsection{Material parameters}

A classical damage mechanics law is used for the first gradient constitutive law [45]. The concrete material parameters are provided in Table 1.

The elastic modulus $\mathrm{B}$ for the second gradient constitutive law is considered to be equal to $1.5 \mathrm{MN}$. A way to choose this parameter is discussed in Section 4.4. The first gradient material law and the second gradient are hereafter considered to be uncoupled.

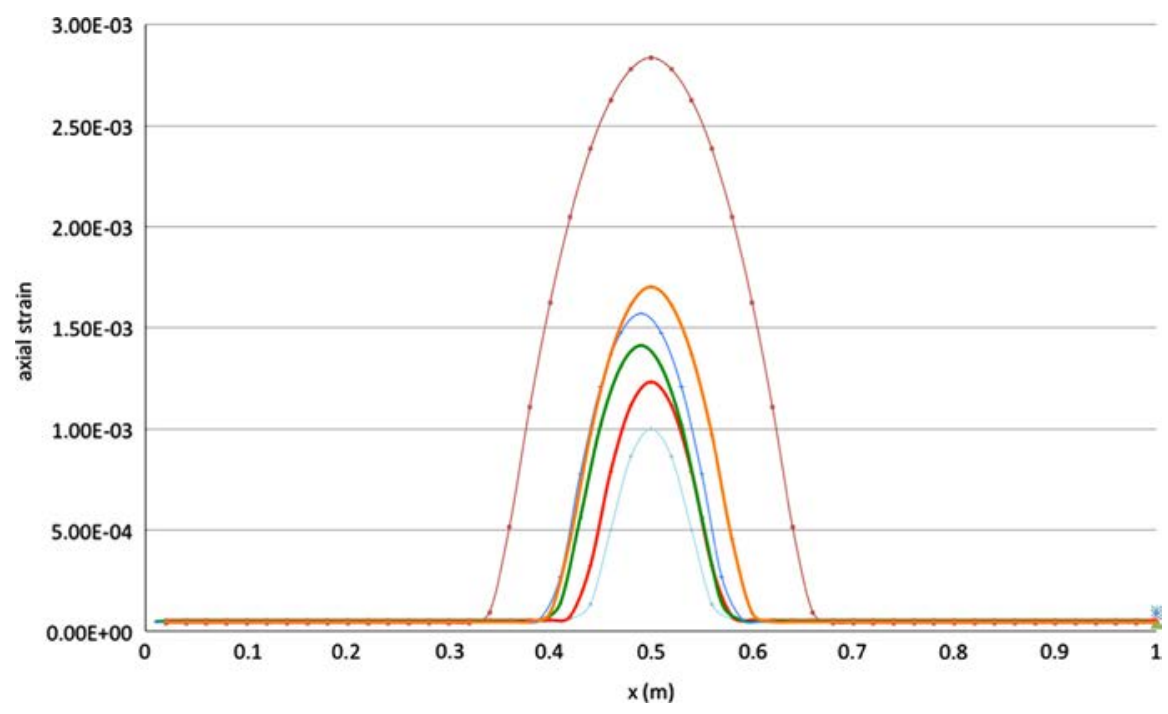

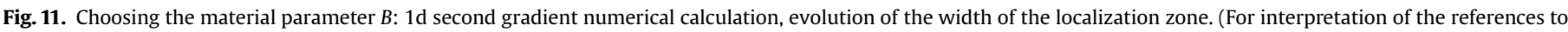
colour in this figure caption, the reader is referred to the web version of this paper.)

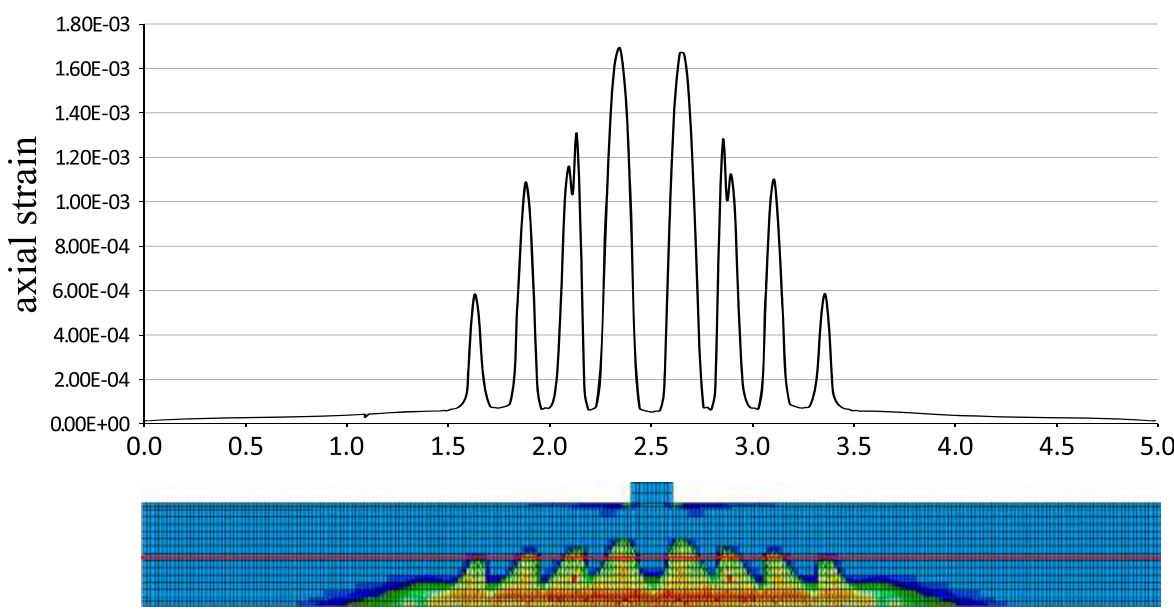

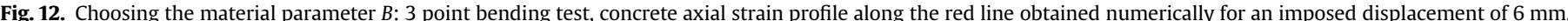
(For interpretation of the references to colour in this figure caption, the reader is referred to the web version of this paper.) 


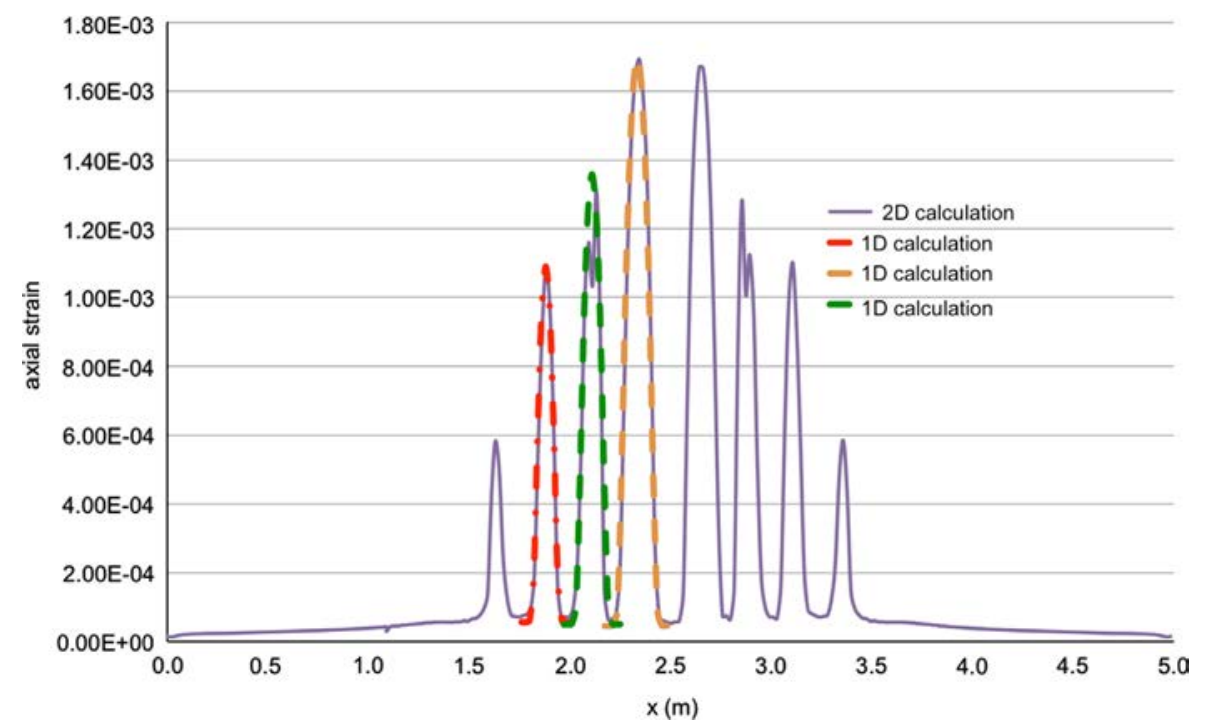

Fig. 13. Choosing the material parameter $B$ : comparison of the strain profiles coming from the $1 \mathrm{~d}$ second gradient model and the three point bending tests. (For interpretation of the references to colour in this figure caption, the reader is referred to the web version of this paper.)

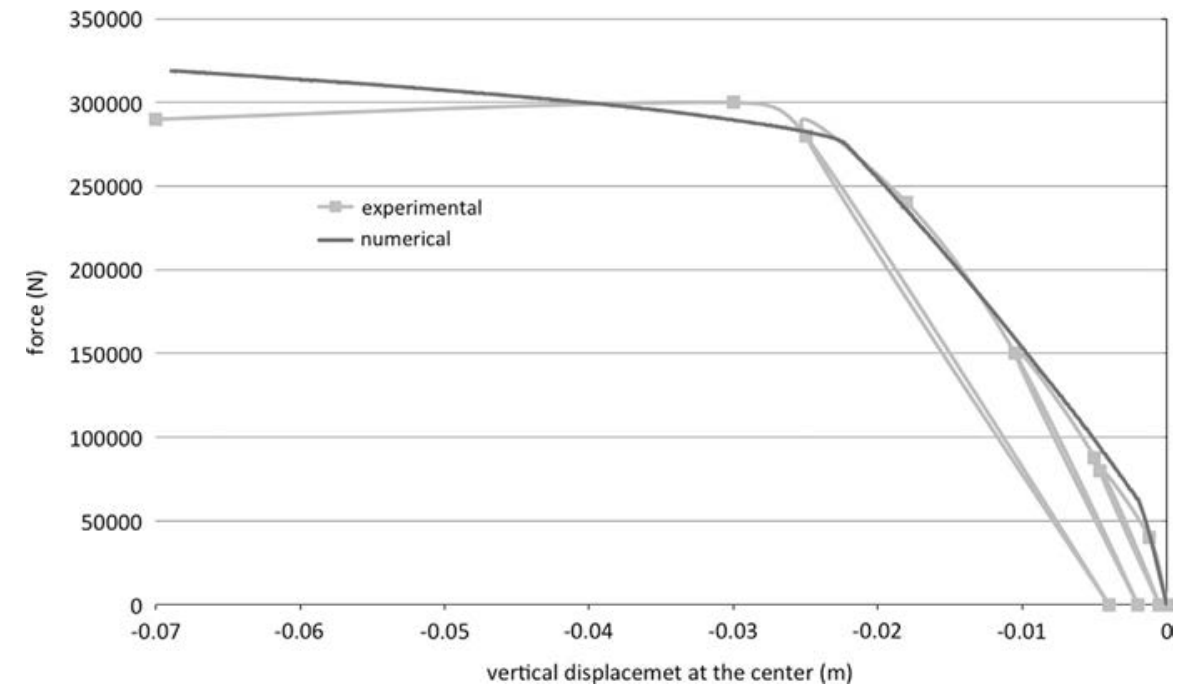

Fig. 14. 3 point bending test: force-displacement curve.

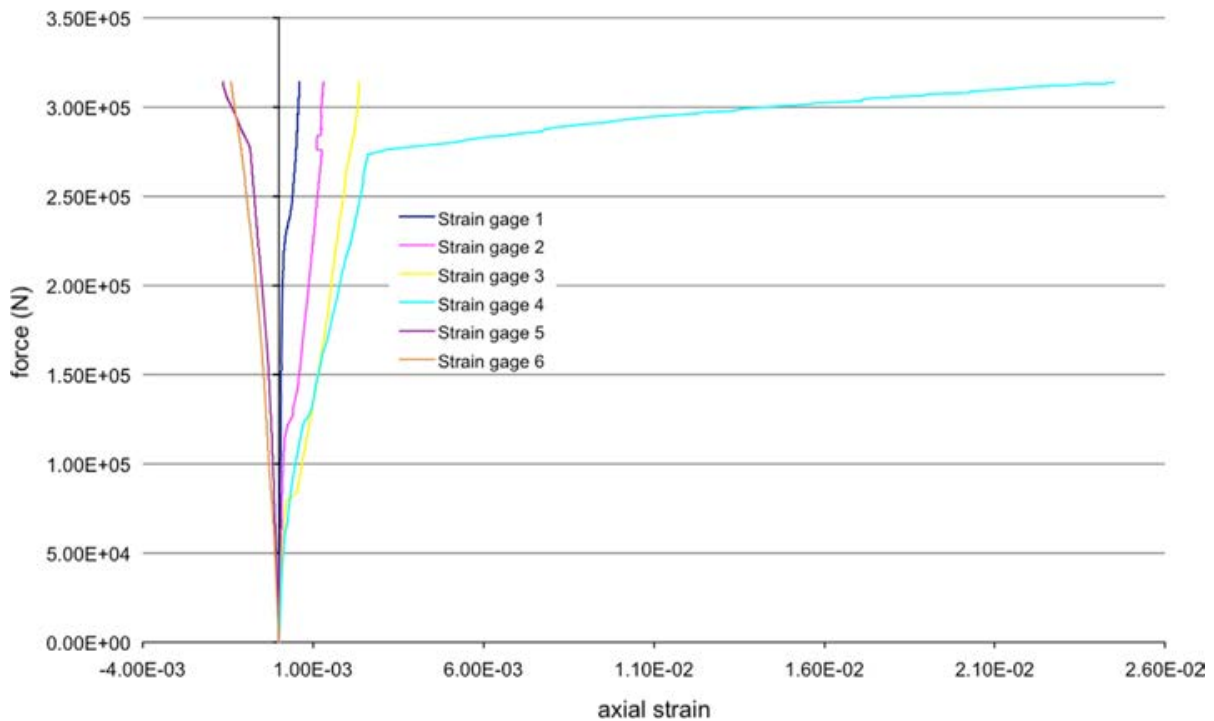

Fig. 15. 3 point bending test: force versus axial strains obtained numerically at different positions on the reinforcement bars. 


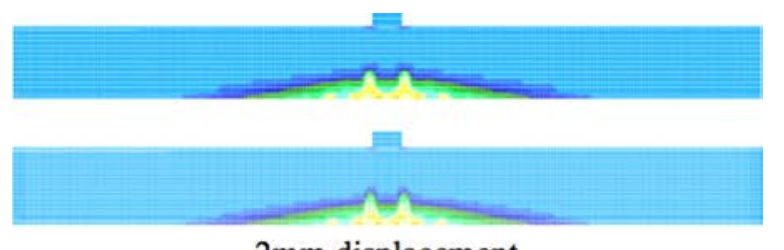

$2 \mathrm{~mm}$ displacement

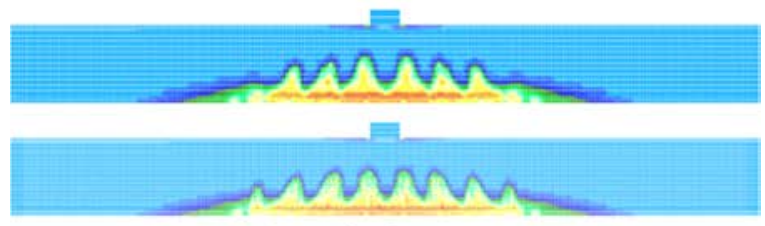

$4 \mathrm{~mm}$ displacement
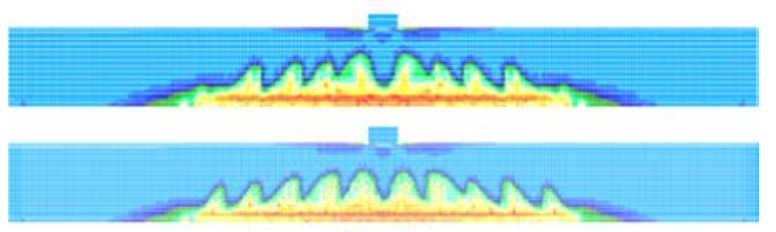

$6 \mathrm{~mm}$ displacement

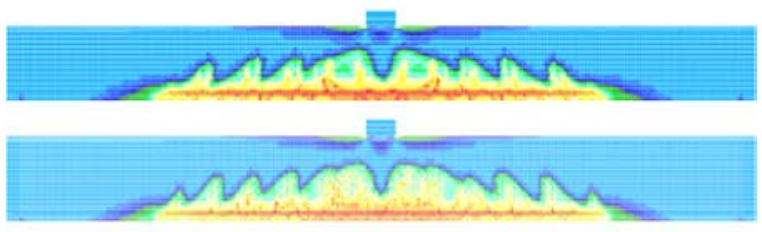

$8 \mathrm{~mm}$ displacement
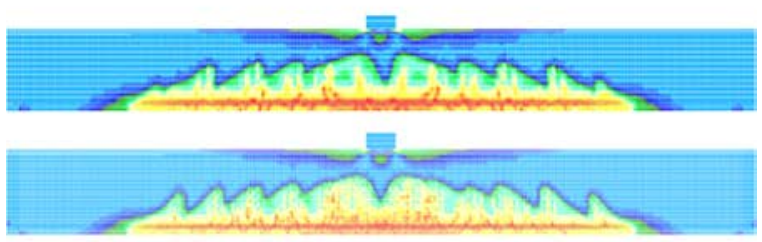

$10 \mathrm{~mm}$ displacement

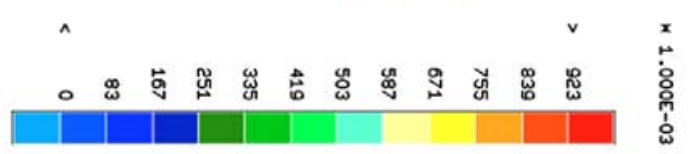

Damage scale

Fig. 16. 3 point bending test: distribution of the damage variable in concrete at different steps for the two meshes.

An elastic perfectly plastic law is used for the reinforcement. The following parameters are adopted, Tables 2 and 3 (where $\sigma_{y}$ the yield stress and HA states for high adherence).

\subsection{Choosing the material parameter $B$}

As discussed in Section 3.3, the analytical solution provided in Eq. (18) can be used as an indicator of the initial size of the localization and its evolution. As damage increases, the slope of the first gradient law decreases (in absolute value) and the width of the band is increased.

The above argument is verified hereafter for the case of the three point bending test: A $1 \mathrm{~d}$ second gradient calculation is performed on a concrete specimen adopting the parameters of Table 1 and an elastic modulus $B$ equal to $1.5 \mathrm{MN}$. Eq. (18) provides an initial width of the localization band (approximately) equal to $15 \mathrm{~cm}$. In Fig. 11, the evolution of the profile of the concrete axial strains for different values of imposed displacements coming from the $1 \mathrm{~d}$ calculation is provided. At the beginning of the loading the width of the localization zone is (approximately) equal to $15 \mathrm{~cm}$. At the end of the loading it is found (approximately) to be equal to $30 \mathrm{~cm}$. Fig. 12 presents the numerical profile of the concrete axial strains for the three point bending test along the red line for an imposed displacement of $6 \mathrm{~mm}$. The strain distribution presents several strain bands similar to the one found for the 1d case, Fig. 11. Comparison is more obvious in Fig. 13 where the strain distributions coming from the $1 \mathrm{~d}$ model (dotted lines) and the three point bending test (continuous lines) are plotted. The same "peak strains" (the maximum strain found in the band) are found (see red, green and orange lines in Figs. 11 and 13).

From the above it is obvious that for a three point bending test a 1d second gradient model can be used to calibrate the parameter $B$ and thus the initial width of the localization zone and its evolution.

\subsection{Numerical results}

Fig. 14 presents the numerical force versus displacement (measured at the centre of the beam) curve compared to the experimental one (note: during the experiment the beam was loaded and unloaded cyclically whereas in the simulation the beam is loaded with a monotonic increasing displacement). At this global level results for both meshes were identical. The force displacement graph exhibits the classical reinforced concrete behaviour in three stages: In the first stage, concrete and steel stay both in the elastic regime; then concrete starts to damage and the slope of the force displacement curve changes. Finally, steel enters a plastic phase and a second change in the slope appears. The numerical model provides however more stiff results at the last levels of the loading.

Fig. 15 shows the evolution of the numerically obtained axial strains at different positions on the reinforcement bars as a function of the global force. Results are found to be comparable to the experimental data [55,56]. The model is able to capture positive and negative strains and thus to distinguish the parts of beam in traction or in compression. The strain gauge 4 is inside a strain localization zone, this is why the corresponding strain value is important.

Fig. 16 shows the distribution of the damage variable in concrete at different stages of loading and for the two mesh sizes. The damage distributions for the two meshes are similar (mesh objectivity) but not exactly the same. This is due to the fact that the second gradient method does not restore the unicity of the solution and small changes in the model can trigger different solutions. In contrast to a classical continuum mechanics model (without any regularization technique), the different solutions are however physically acceptable. For similar bending tests, classical non-local damage models which define an equivalent strain by averaging over a certain distance (material length parameter) have sometimes a tendency to artificially develop damage on the upper, compressed part of the beam (even if the local strain is not high enough to cause compressive damage). This is due to the principle of averaging over an area. There is no such problem with this model as the variables are local.

The damage pattern develops numerically with sudden peaks which experimentally correspond to developing cracks. The crack opening cannot be modelled directly in this simulation as the displacement field remains continuous, but it can be approximated from the damage model by simply measuring the displacement jump between two points located on the opposite sides of a damaged zone. This obviously works only when the damaged bands are clearly separated. The width and separation of the damage bands can be controlled by changing the internal length, 
which in our case means changing the slope of either or both the first gradient and second gradient constitutive laws.

\section{Conclusions}

A second gradient model is adopted to simulate the behaviour of plane concrete and reinforced concrete structural elements using a classical damage mechanics law. The contribution is clearly a first step in the modelling of concrete failure with such type of models and the authors tried to highlight the advantages and drawbacks of the approach.

More specifically, objective (mesh independent) global and local results are obtained and damage is localized into bands whose width is controlled by the model parameters. The uniqueness of the solution is not restored and the evolution of the localization zone is discussed. In its actual form, the model provides a higher residual stress and spreading damage/strain fields. In a forthcoming article the authors will try to address some of the shortcomings of the current formulation (kernel of the regularization operator, enlargement of the damage band, spurious cohesive forces resulting from the higher order stress tensor). These results are encouraging and represent the first steps toward a wider use of second gradient models for concrete structures.

\section{Acknowledgements}

The authors would like to thank the ANR MEFISTO (Maitrise durable de la fissuration des infrastructures en béton, projet ANR 2008 Sustainable Cities Program, Project number: VD08 323065, 2011) and the ANR GEOBRIGDE (Geobridge - Failure of cohesive geomaterials: bridging the scales, Projet ANR-09-BLAN-0096).

\section{References}

[1] R. Hill, J. Hutchinson, Bifurcation phenomena in the plane tension test, J. Mech. Phys. Solids 23 (4) (1975) 239-264.

[2] J.R. Rice, The Localization of Plastic Deformation, Division of Engineering, Brown University, Theoretical and Applied Mechanics, W.T. Koiter, ed., NorthHolland Publishing Company, 1976.

[3] J.W. Rudnicki, J. Rice, Conditions for the localization of deformation in pressure-sensitive dilatant materials, J. Mech. Phys. Solids 23 (6) (1975) 371-394.

[4] J. Desrues, G. Viggiani, Strain localization in sand: an overview of the experimental results obtained in grenoble using stereophotogrammetry, Int J. Numer. Anal. Methods Geomech. 28 (4) (2004) 279-321.

[5] I. Vardoulakis, M. Goldscheider, G. Gudehus, Formation of shear bands in sand bodies as a bifurcation problem, Int. J. Numer. Anal. Methods Geomech. 2 (2) (1978) 99-128.

[6] I. Vardoulakis, Shear band inclination and shear modulus of sand in biaxial tests, Int. J. Numer. Anal. Methods Geomech. 4 (2) (1980) 103-119.

[7] E. Aifantis, On the microstructural origin of certain inelastic models, J. Eng. Mater. Technol. 106 (4) (1984) 326-330.

[8] G. Pijaudier-Cabot, Z.P. Bažant, Nonlocal damage theory, J. Eng. Mech. 113 (10) (1987) 1512-1533.

[9] J. Sulem, I. Vardoulakis, Bifurcation Analysis in Geomechanics, Blackie Academic \& Professional, an imprint of Chapman \& Hall, Wester Cleddens Road, Bishopbriggs, Glasgow, 1995.

[10] M. Jirásek, Z.P. Bažant, Inelastic Analysis of Structures, John Wiley \& Sons, Ltd. Baffins Lane, Chichester, West Sussex, England, 2002.

[11] M. Jirásek, Mathematical analysis of strain localization, Rev. Eur. Génie Civil 11 (7) (2007) 977-991.

[12] R. Fernandes, Modélisation numérique objective des problèmes couplés hydromécaniques dans le cas des géomatériaux (Ph.D. thesis), Université Joseph-Fourier-Grenoble I, 2009 〈http://tel.archives-ouvertes.fr/tel-00517702〉.

[13] A. Hillerborg, M. Modéer, P.-E. Petersson, Analysis of crack formation and crack growth in concrete by means of fracture mechanics and finite elements, Cem. Concr. Res. 6 (6) (1976) 773-781.

[14] Z.P. Bažant, Instability, ductility. and size effect in strain-softening concrete, J. Eng. Mech. Div. 102 (2) (1976) 331-344.

[15] Z.P. Bažant, B. Oh, Crack band theory for fracture of concrete, Matér. Constr. 16 (3) (1983) 155-177.

[16] S. Pietruszczak, Z. Mroz, Finite element analysis of deformation of strainsoftening materials, Int. J. Numer. Methods Eng. 17 (3) (1981) 327-334.
[17] A. Needleman, Material rate dependence and mesh sensitivity in localization problems, Comput. Methods Appl. Mech. Eng. 67 (1) (1988) 69-85.

[18] S. Forest, E. Lorentz, Localization and regularization, in: J. Besson (Ed.), Local Approach to Fracture, Les Presses de l'Ecole des Mines de Paris, 2004.

[19] R. Peerlings, R. De Borst, W. Brekelmans, J. de Vree, Gradient enhanced damage for quasi-brittle materials, Int. J. Numer. Methods Eng. 39 (1996) 3391-3403.

[20] A. Krayani, G. Pijaudier-Cabot, F. Dufour, Boundary effect on weight function in nonlocal damage model, Eng. Fract. Mech. 76 (14) (2009) 2217-2231.

[21] C. Giry, F. Dufour, J. Mazars, Stress-based nonlocal damage model, Int. J. Solids Struct. 48 (25) (2011) 3431-3443.

[22] S.Y. Alam, P. Kotronis, A. Loukili, Crack propagation and size effect in concrete using a non local damage model, Eng. Fract. Mech. 109 (2013) 246-261.

[23] R. Peerlings, R. De Borst, W. Brekelmans, M. Geers, Localisation issues in local and nonlocal continuum approaches to fracture, Eur. J. Mech. A: Solids 21 (2) (2002) 175-189.

[24] R. Peerlings, J. de Vree, Gradient enhanced damage for quasi-brittle materials, Int. J. Numer. Methods Eng. 39 (1996) 3391-3403.

[25] M. Frémond, B. Nedjar, Damage, gradient of damage and principle of virtual power, Int. J. Solids Struct. 33 (8) (1996) 1083-1103.

[26] E. Lorentz, Modélisation et simulation numérique de l'endommagement des structures, Université Pierre et Marie Curie-Paris VI, HDR, 2008 〈http://tel. archives-ouvertes.fr/tel-00473965〉.

[27] E. Lorentz, V. Godard, Gradient damage models: toward full-scale computations, Comput. Methods Appl. Mech. Eng. 200 (21) (2011) 1927-1944.

[28] N. Moës, C. Stolz, P.-E. Bernard, N. Chevaugeon, A level set based model for damage growth: the thick level set approach, Int. J. Numer. Methods Eng. 86 (3) (2011) 358-380.

[29] E. Cosserat, F. Cosserat, M. Brocato, K. Chatzis, Théorie des Corps Déformables, A. Hermann, Paris, 1909.

[30] R. Toupin, Elastic materials with couple-stresses, Arch. Ration. Mech. Anal. 11 (1) (1962) 385-414.

[31] R. Mindlin, Micro-structure in linear elasticity, Arch. Ration. Mech. Anal. 16 (1) (1964) $51-78$.

[32] R.D. Mindlin, Second gradient of strain and surface-tension in linear elasticity, Int. J. Solids Struct. 1 (4) (1965) 417-438.

[33] P. Germain, La méthode des puissances virtuelles en mécanique des milieux continues: Première partie: théorie du second gradient, J. Méc. 12 (1973) 235-274.

[34] P. Germain, The method of virtual power in continuum mechanics, Part 2: microstructure, SIAM J. Appl. Math. 25 (3) (1973) 556-575.

[35] R. Chambon, D. Caillerie, N. El Hassan, Étude de la localisation unidimensionnelle à l'aide d'un modèle de second gradient, C.R. Acad. Sci Sér. IIb 323 (1996) 231-238.

[36] R. Chambon, D. Caillerie, N. El Hassan, One-dimensional localisation studied with a second grade model, Eur. J. Mech. A: Solids 17 (4) (1998) 637-656.

[37] R. Chambon, D. Caillerie, T. Matsuchima, Plastic continuum with microstructure, local second gradient theories for geomaterials: localization studies, Int. J. Solids Struct. 38 (46) (2001) 8503-8527.

[38] T. Matsushima, R. Chambon, D. Caillerie, Second gradient models as a particular case of microstructured models: a large strain finite elements analysis, C.R. Acad. Sci. Ser. IIB Mech. Phys. Astron. 328 (2) (2000) 179-186.

[39] T. Matsushima, R. Chambon, D. Caillerie, Large strain finite element analysis of a local second gradient model: application to localization, Int. J. Numer. Methods Eng. 54 (4) (2002) 499-521.

[40] F. Calvetti, G. Combe, J. Lanier, Experimental micromechanical analysis of a $2 d$ granular material: relation between structure evolution and loading path, Mech. Cohesive-frict. Mater. 2 (2) (1997) 121-163.

[41] T. Matsushima, H. Saomoto, Y. Tsubokawa, Y. Yamada, Grain rotation versus continuum rotation during shear deformation of granular assembly, Soils Found. 43 (4) (2003) 95-106.

[42] P. Kotronis, S. Al Holo, P. Bésuelle, R. Chambon, Shear softening and localization: modelling the evolution of the width of the shear zone, Acta Geotech. 3 (2) (2008) 85-97.

[43] J.C. Moullet, Etude numérique de la bifurcation et de la localisation à l'aide de modèle de second gradient (Ph.D. thesis), Université Joseph-Fourier-Grenoble I, 2003.

[44] P. Bésuelle, Implémentation d'un nouveau type d'élément fini dans le code lagamine pour une classe de lois à longueur interne, Internal Report, FNRS, Belgique, 2003, pp. 1-17.

[45] J. Mazars, Application de la mécanique de l'endommagement au comportement non linéaire et à la rupture du béton de structure, thèse de doctorat d'état de l'Université Paris VI, 1984.

[46] R. Chambon, S. Crochepeyre, R. Charlier, An algorithm and a method to search bifurcation points in non-linear problems, Int. J. Numer. Methods Eng. 51 (3) (2001) 315-332.

[47] R. Chambon, J.C. Moullet, Uniqueness studies in boundary value problems involving some second gradient models, Comput. Methods Appl. Mech. Eng. 193 (27) (2004) 2771-2796.

[48] P. Kotronis, Stratégies de modélisation de structures en béton soumises à des chargements sévères, université Joseph-Fourier-Grenoble I, HDR, 2008 〈http:// tel.archives-ouvertes.fr/tel-00350461>.

[49] P. Bésuelle, R. Chambon, F. Collin, Switching deformation modes in postlocalization solutions with a quasibrittle material, J. Mater. Struct. 1 (2006) $1115-1134$.

[50] S. Rolshoven, Nonlocal plasticity models for localized failure (Ph.D. thesis), École Polytechnique fédérale de Lausanne, 2003. 
[51] S. Cuvilliez, F. Feyel, E. Lorentz, S. Michel-Ponnelle, A finite element approach coupling a continuous gradient damage model and a cohesive zone model within the framework of quasi-brittle failure, Comput. Methods Appl. Mech. Eng. 237 (2012) 244-259.

[52] A. Simone, G.N. Wells, L.J. Sluys, From continuous to discontinuous failure in a gradient-enhanced continuum damage model, Comput. Methods Appl. Mech. Eng. 192 (41-42) (2003) 4581-4607.

[53] A. Simone, L.J. Sluys, The use of displacement discontinuities in a ratedependent medium, Comput. Methods Appl. Mech. Eng. 193 (27-29) (2004) 3015-3033 (Computational failure mechanics for geomaterials).

[54] C. Comi, S. Mariani, U. Perego, An extended fe strategy for transition from continuum damage to mode i cohesive crack propagation, Int. J. Numer. Anal. Methods Geomech. 31 (2) (2007) 213-238.
[55] L. Jason, Réponse au benchmark statique monotone du projet national ceos.fr, rapport CEA SACLAY, DM2S/SEMT/LM2S, Rapport ANR MEFISTO, 2008.

[56] S. Ghavamian, I. Carol, A. Delaplace, Discussions over MECA project results, Rev. Franaise Génie Civil 7 (5) (2003) 543-581.

[57] S. Grange, P. Kotronis, J. Mazars, Numerical modelling of the seismic behaviour of a 7-story building: Nees benchmark, Mater. Struct. 42 (10) (2009) 1433-1442.

[58] S. Grange, L. Botrugno, P. Kotronis, C. Tamagnini, The effects of soil-structure interaction on a reinforced concrete viaduct, Earthq. Eng. Struct. Dyn. 40 (1) (2011) 93-105. 